\title{
TEACHING AND LEARNING
}

\section{Clinicians' knowledge of informed consent}

\author{
Lisa Fisher-Jeffes, Charlotte Barton, Fiona Finlay
}

J Med Ethics 2007;33:181-184. doi: 10.1136/jme.2006.016758

See end of article for authors' affiliations ......................

Correspondence to: F Finlay, Child Health Department, Newbridge Hill Bath BAI 3QE, UK; Fiona. finlay@banes-pct.nhs.uk

Received 17 March 2006 Revised 17 March 2006 Accepted 4 June 2006

\begin{abstract}
Objective: To audit doctors' knowledge of informed consent.
Design: 10 consent scenarios with "true", "false", or "don't know" answers were completed by doctors who care for children at a large district general hospital. These questions tested clinicians' knowledge of who could give consent in different clinical situations.

Setting: Royal United Hospital, Bath, UK.

Results: 51 doctors participated (25 paediatricians and 26 other clinicians). Paediatricians scored higher than other clinicians (average correct response 69\% v 49\%). Only 36\% (9/25) of paediatricians and $8 \%$ (2) 26) of other clinicians realised that the biological father of a child born before 1 December 2003 needed a court order or a parental responsibility agreement to acquire parental responsibility, and thus be able to consent on behalf of his child, if he was not married to the child's mother. Non-paediatric clinicians were unsure or incorrect when tested on situations where people with parental responsibility do not agree, or where young people ( $<16$ years), who are Fraser competent do not want to consult their parents. Most clinicians did not know that the parents of a 20 -year-old man with severe learning difficulties are unable to consent to surgery on his behalf, and many non-paediatricians were unclear on who could give consent when a child lived with foster parents.

Conclusion: Clinicians who obtain consent for the treatment of children need to increase their knowledge on who is able to give informed consent to ensure best (legal and safe) practice.
\end{abstract}

C onsent must be obtained before starting treatment or investigation, or providing personal care, for a patient. ${ }^{1}$ For consent to be valid, the person giving consent must be capable of making particular decisions (competence) and acting voluntarily, and be provided with enough information to make the decision. Information should be available about what the treatment will include: benefits and risks, implications of not having the treatment and the alternatives available.

The General Medical Council states that "doctors should do their best to find out about patients' individual needs and priorities when providing information about treatment options". ${ }^{2}$ Doctors should establish a rapport with their patients and enter into a dialogue with them about treatment; "lingering paternalism is not part of good practice, and cannot be excused by being disguised as mere beneficent intent or 'doctor knows best'.

Although young children may have views about their treatment and should be listened to, they are not competent to give informed consent and this should be obtained from someone with parental responsibility. The Children Act $1989^{4}$ sets out people who may have parental responsibility:

- The child's parents' if married to each other at the time of conception or birth

- The child's mother, but not father, if they were not married, unless the father has acquired parental responsibility through a court order or a parental responsibility agreement, or the couple subsequently marry. To have effect, a parental responsibility agreement must be signed and witnessed by a justice's clerk or court officer and it must be filed at the High Court. (This has recently been amended, so that the father of a child born on or after 1 December 2003 has parental responsibility if his name appears on the birth certificate. ${ }^{5}$ )

- The child's legally appointed guardian-appointed by a court or by a parent with parental responsibility in the event of their own death.
- A person in whose favour a court has made a residence order for the child.

- A local authority designated in a care order in respect of the child (but not where the child is being looked after under Section 20 of the Children Act, also known as "accommodated" or in voluntary care).

- A local authority or authorised person who holds an emergency protection order in respect of the child.

Although there is no English statute setting out the principles of consent, case law on consent has evolved over time. Although competence is assumed in those $>16$ years of age, Lord Fraser in 1985, in the Gillick ruling, established that children $<16$ years of age, who have sufficient understanding and intelligence to enable them to understand fully what is required in a proposed intervention, will also have the capacity to consent. ${ }^{6}$ This is sometimes described as "Gillick competent" or "Fraser competent". As the understanding required for different interventions will vary, a child $<16$ years may therefore have the capacity to consent to some interventions but not to others.

It is important that those who work with children and young people have a thorough understanding of who may consent. Our study aimed to compare clinicians' understanding of consent practice against agreed standards as documented in the Department of Health publications Reference guide to consent for examination or treatment and Seeking consent: working with children. ${ }^{17}$

\section{METHOD}

A questionnaire with 10 scenarios involving children was designed, asking questions with "true, false or don't know" answers. The answers were prevalidated using the Department of Health Guidelines. ${ }^{17}$

Doctors from different specialties were asked to participate in the study, anonymously completing the questionnaire. 


\section{RESULTS}

In all, 51 doctors ( $96.2 \%$ of those approached) took part in the study -2 radiologists, 4 ophthalmologists, 2 urologists, 3 ENT surgeons, 5 orthopaedic surgeons, 10 general surgeons and 25 paediatricians.

Responses were analysed and each doctor's score was calculated, comparing the score for paediatricians with other clinicians for each scenario.

\section{Scenario 1}

A 7-year old attends a renal scan with his biological father. The father is not married to the boy's mother, but lives with them. Does he need a court order before he can consent for the procedure to be performed on his son?

Answer: Yes.

Only $36 \%(9 / 25)$ of the paediatricians and $8 \%(2 / 26)$ of the others answered correctly.

\section{Scenario 2}

An 8-year-old presents to outpatient with her stepmother, who has not adopted her. She is due to have a strabismus correction in a week and the consultant has explained the procedure to her parents on a previous visit. Is her stepmother, who accompanies her today, able to sign the consent form?

Answer: No.

Most respondents knew the correct answer-92\% (23/25) of the paediatricians and $92 \%(24 / 26)$ of the others answered correctly.

\section{Scenario 3}

A child with cerebral palsy, secondary to shaken baby syndrome, who is under a care order, arrives at the surgical ward with his new foster carers. He is due to have corrective hip surgery.

a. Can the foster carers consent?

Answer: No.

In total, $72 \%(18 / 25)$ of the paediatricians and $38 \%(10 / 26)$ of the others answered correctly.

b. Can the social worker consent?

Answer: Yes.

In total, $72 \%(18 / 25)$ of the paediatricians and $38 \%(10 / 26)$ of the others answered correctly.

\section{Scenario 4}

A 15-year-old boy is hit by a bus. He is unconscious and has signs of peritonism, suggesting serious intra-abdominal bleeding. He needs an urgent laparotomy. The surgeons want consent from somebody-can they ask the following for consent?

a. Grandmother, who is with him in accident and emergency. Answer: No.

In total, $48 \%(12 / 25)$ of the paediatricians and $42 \%$ (11/26) of the others answered correctly.

b. Mother, who has phoned from work.

Answer: Yes.

Most (92\% 23/25) of the paediatricians and 69\% (18/26) of the others answered correctly.

c. Surgeon performing the procedure.

Answer: No.

Only $12 \%(3 / 25)$ of the paediatricians and $8 \%(2 / 26)$ of the others answered correctly. On further discussion with some of the participants in the survey, most knew that the surgeon could proceed with surgery but were confused by the wording of the question and answered "no". The surgeon is unable to give consent but is able to operate if urgent treatment is required, acting in the young person's best interests.

\section{Scenario 5}

John (fictitious name), aged 5, has been diagnosed as having leukaemia. His parents, who are married to each other, disagree on whether or not to opt for chemotherapy. Mum is determined that he should have it, but Dad is refusing. Can the health professionals obtain consent from her, even though Dad is refusing?

Answer: Yes.

In total $64 \%(16 / 25)$ of the paediatricians and 36\% (9/25) of the others answered correctly.

\section{Scenario 6}

A 15-year-old girl presents to a family planning clinic, asking for an abortion. She does not wish to tell her parents that she is pregnant and asks you not to tell them. You explain the risks of the procedure and what it entails and she shows from her responses that she understands.

a. Can she consent to the procedure herself?

Answer: Yes.

All $(100 \% ; 25 / 25)$ of the paediatricians and $69 \%(18 / 26)$ of the others answered correctly.

b. Can you proceed without telling her parents?

Answer: Yes.

All $(100 \% ; 25 / 25)$ of the paediatricians and 58\% (15/26) of the others answered correctly.

\section{Scenario 7}

A 6-week-old baby is admitted to the children's ward with pyloric stenosis. The surgeons believe that they need to operate on the child. His 15-year-old mother seems to understand the implications of surgery. Can she consent to this?

Answer: Yes.

In total $(96 \% ; 24 / 25)$ of the paediatricians and $81 \%(21 / 26)$ of the others answered correctly.

\section{Scenario 8}

A 15-year-old boy who has Down's syndrome attends dental clinic after school with his uncle. His parents have not signed the consent form for his dental extraction that is scheduled for today. He appears to fully understand the implications.

a. Can he sign the consent form himself?

Answer: Yes.

In total, $(84 \% ; 21 / 25)$ of the paediatricians and 54\% (14/26) of the others answered correctly.

b. Can the uncle sign on behalf of his parents?

Answer: No.

In total, $(88 \% ; 24 / 25)$ of the paediatricians and $69 \%(14 / 26)$ of the others answered correctly.

\section{Scenario 9}

A 4-year-old child is brought from school to the accident and emergency department with a history of severe abdominal pain. The surgeon who assesses him is concerned that he may have perforated his appendix. His parents are not contactable. Can the teacher consent to him having treatment?

Answer: No.

Most $(68 \% ; 17 / 25)$ of the paediatricians and $62 \%(16 / 26)$ of the others answered correctly.

\section{Scenario 10}

A 20-year old with severe learning difficulties needs a gastrostomy.

a. Can his father consent to the procedure?

Answer: No.

In total, $(27 \% ; 8 / 25)$ of the paediatricians and $24 \%(7 / 26)$ of the others answered correctly.

b. Can the doctor consent to the procedure? 
Answer: No.

In total, $(52 \% ; 13 / 25)$ of the paediatricians and $19 \%(5 / 26)$ of the others answered correctly.

\section{DISCUSSION}

It is important that clinicians are familiar with consent law. In a previous study looking at knowledge of consent practice, the performance of doctors was generally better than that of nondoctors, ${ }^{8}$ and in another study $58 \%$ of psychiatrists, $34 \%$ of geriatricians, $20 \%$ of general practitioners and $15 \%$ of students correctly answered questions on capacity to consent to or refuse medical treatment. ${ }^{9}$ Although the results presented here are slightly more encouraging, the study shows that further education about consent is required.

Mothers always have parental responsibility unless it has been taken away from them through child protection proceedings, but few respondents were aware that unmarried fathers do not automatically have parental responsibility (scenario 1). The Children Act $1989^{4}$ clearly defines parental responsibility. It can be acquired by people other than the child's natural parents-for example, a legally appointed guardian or a local authority-allowing them to consent on a child's behalf.

The consent of one person with parental responsibility is sufficient, although it is ideal if agreement can be achieved (scenario 5). Step-parents, grandparents and other relatives do not have parental responsibility (scenarios 2, 4 and 8). Foster parents do not have parental responsibility unless legally appointed by the court (scenario 3).

Once children have reached 16 years of age they are presumed in law to be competent to give consent, whereas those $<16$ are not automatically presumed to be legally competent. In 1985, Lord Fraser, in the Gillick ruling, established that children $<16$ years of age who are capable of fully understanding the implications of their decisions can give valid consent. All (100\%) of the paediatricians, compared with $69 \%$ of non-paediatricians, responded correctly to the scenario asking if a 15-year-old is able to give consent for a procedure without involving her parents (scenario 6), a situation encountered in their day-to-day practice.

Numerous studies in the literature have looked at the competency of children to make informed treatment decisions. Weithorn $^{10}$ studied subjects aged 9, 14, 18 and 21 using hypothetical treatment dilemmas and concluded that 14-yearolds did not differ from adults in their competency to make treatment decisions. Nine-year-olds seemed less competent to understand treatment information but were able to participate meaningfully in healthcare decision making. There is no specific age at which a child becomes competent. It depends on the child and the complexity of proposals. Pain may reduce competence, but experience of illness may increase it-for example, young children who have had chemotherapy will often have more informed views about further treatment than adults considering treatment. ${ }^{11}{ }^{12}$ It is important that professionals respect the wishes of the child in light of their knowledge, understanding and experience.

If the mother is herself $<16$ years (scenario 7 ), she will only be able to give valid consent for her child's treatment if she herself is Fraser competent. ${ }^{6}$

Inevitably there will be times when children and those with parental responsibility do not agree. The decision of a competent child to accept treatment cannot be over-ridden by a person with parental responsibility. However, the courts have stated that, in exceptional circumstances, if the child refuses treatment, those with parental responsibility may consent on his or her behalf, and treatment can be lawfully given.

Clinicians and parents may not agree and, usually, if parents refuse treatment it will not go ahead. However, if treatment is thought to be crucial the court can be asked to decide on what is in the child's best interests. Sometimes the opposite situation will arise, where the clinicians believe that treatment, which the parents want, is not appropriate and the courts may be asked to rule if an agreement cannot be reached. ${ }^{13}$

It should never automatically be assumed that a child with a physical or learning disability is not competent to make decisions. Many will be competent if information is presented in an appropriate way and they are supported through the process (scenario 8).

There was uncertainty among respondents about consent in an emergency situation (scenarios 4 and 9). However, the position is quite clear- "in an emergency, where consent cannot be obtained, you may provide medical treatment to anyone who needs it, provided the treatment is limited to what is immediately necessary to save life or avoid deterioration in the patient's health". ${ }^{2}$ A person who does not have parental responsibility but who has care of a child can "do what is reasonable in all circumstances for the purpose of safe guarding or promoting the child's welfare" ${ }^{\prime}{ }^{7}$ This might apply to teachers who, in an emergency, could take a child for treatment that was provided on the basis that it was in the child's best interest and no one with parental responsibility was contactable. ${ }^{3}$ In an emergency, a surgeon can perform an operation to save a child's life without formally obtaining consent.

Clinicians were poorly informed about the legal situation regarding an adult who is not competent to consent $-73 \%$ of paediatricians and $76 \%$ of others being unaware that a parent is unable to consent (scenario 10). Legally, in England, Wales and Northern Ireland, no one can give consent to treatment on behalf of another adult, although this will change in England and Wales through the Mental Capacity Act 2005 which comes into force in April 2007. ${ }^{14}$ This act sets out clear legal requirements for assessing competence and treating incompetent patients. The act applies to individual decisions, as an individual may lack the capacity to make complex decisions but may be competent to make others. ${ }^{15}$ As the law currently stands, doctors may treat a patient who lacks capacity, without consent, provided that the treatment is necessary and in the patient's best interests. Even though the views of relatives have no legal status, it is good practice to consult with them. In Scotland, the Adults with Incapacity (Scotland) $\mathrm{Act}^{16}$ allows the courts to appoint a proxy decision-maker on behalf of an incapacitated adult.

Where treatment is not immediately necessary, seeking consent should be seen as an ongoing process, not a one-off event. ${ }^{17}$ Legally, it does not matter whether consent is written, verbal (either in person or over the telephone-scenario 4), or non-verbal (holding out a child's arm for their blood pressure to be taken implies consent). A consent form is only a record and not proof that genuine consent has been obtained, but it is good practice to seek written consent for treatment, which is complex or is associated with significant risk. It is important that the person explaining the treatment or operation is well informed-obtaining consent should not be left to the most junior member of the team whose knowledge of the proposed treatment may be limited. ${ }^{18}$

\section{CONCLUSION}

Consent is a difficult subject and one that clinicians face in their everyday practice.

Case law surrounding consent for treatment of children has evolved over time and it is essential that healthcare professionals keep up to date with legal changes that may influence their practice. Although undergraduate curricula cover "ethics and the law", this topic deserves more attention on postgraduate study days. 
It is important that parents and children are informed about proposed treatment and that children are listened to so that they can participate in decision making. By ensuring that informed consent is ethically and legally obtained, complaints and litigation claims should diminish and there should be greater patient and professional satisfaction. ${ }^{19}$

\section{Authors' affiliations}

Lisa Fisher-Jeffes, Royal United Hospital, Combe Park, Bath, UK

Charlotte Barton, Taunton Road Medical Centre, Bridgwater, Somerset, UK Fiona Finlay, Child Health Department, Newbridge Hill, Bath, UK

Competing interests: None.

\section{REFERENCES}

1 Department of Health. Reference guide to consent for examination or treatment. London: Department of Health, 2001.

2 General Medical Council. Seeking patients' consent: the ethical considerations London: General Medical Council, 1998

3 Worthington R. Clinical issues on consent: some philosophical concerns. J Med Ethics 2002;28:377.

4 Children Act 1989. Families need fathers. England and Wales, 1991.
5 Adoption and Children Act 2002 (Commencement No 4) Order 2003.

6 Gillick $v$ West Norfolk and Wisbech Area Health Authority 1985, 3 AER 402.

7 Department of Health. Seeking consent: working with children. London: Department of Health, 2001.

8 Chadha NK, Repanos C. How much do healthcare professionals know about consent? A Bristol Experience. Surgeon 2004;2:328-33.

9 Jackson E, Warner J. How much do doctors know about consent and capacity? $J$ R Soc Med 2002;95:601-3.

10 Weithorn LA, Campbell SB. The competency of children and adolescents to make informed treatment decisions. Child Dev 1982;53:1589-98.

11 Ethics advisory committee membership. Witholding or withdrawing life sustaining treatment in children: a framework for practice. In: Royal College of Paediatrics and Child Health. 2nd edn. May, 2004:22.

12 Lacher V. Consent, competence and confidentiality. BMJ 2005;330:353-6.

13 NHS Trust $v$ Wyatt (2004) EWHC 2247.

14 Mental capacity Act 2005. www.opsi.gov.uk/act/acts2005/20050009.htm.

15 Corfield L, Granne I. Treating non-competent patients. BMJ 2005;331:1353-4.

16 Adults with incapacity (Scotland) Act 2000. http://www.opsi.gov.uk/ legislation/scotland/acts2000/20000004.htm.

17 British Medical Association. BMA consent tool kit, http://www.bma.org.uk/ ap.nsf/Content/consenttk2.

18 Houghton DJ, Williams S, Bennett JD, et al. Informed consent: patients' and junior doctors' perceptions of the consent procedure. Clin Otolaryngol Allied Sci 1997;22:515-18.

19 Pape T. Legal and ethical considerations of informed consent. AORN J 1997;65:1122-7.

\section{bmjupdates+}

bmiupdates+ is a unique and free alerting service, designed to keep you up to date with the medical literature that is truly important to your practice.

bmjupdates+ will alert you to important new research and will provide you with the best new evidence concerning important advances in health care, tailored to your medical interests and time demands.

Where does the information come from?

bmjupdates+ applies an expert critical appraisal filter to over 100 top medical journals A panel of over 2000 physicians find the few 'must read' studies for each area of clinical interest

Sign up to receive your tailored email alerts, searching access and more...

www.bmjupdates.com 